\title{
Use of hair dyes by patients with breast cancer: a case-control study
}

\author{
L J KINLEN, R HARRIS, A GARROD, K RODRIGUEZ
}

British Medical fournal, 1977, 2, 366-368

\section{Summary}

The recent finding that many permanent and semipermanent hair dyes are strongly mutagenic in a laboratory test, together with the fact that single female hairdressers had higher than expected death rates from breast cancer in 1959-63, prompted a study into the use of hair dyes by patients with breast cancer and by matched controls

There was no difference between the patients and their controls in their use of hair dyes. There were also no significant differences between the two groups when the analysis was confined to women who had used dyes over four years and over nine years before diagnosis. The only significant findings were a higher proportion of past or present smokers among women aged over 50 who used hair dyes and an association between hair dye use and age at first pregnancy.

Further epidemiological studies are clearly needed in view of the mutagenicity found in the Ames test, ${ }^{1}$ and the fact that several human carcinogens are also mutagenic according to this test.

\section{Introduction}

In 1975 Ames et al $^{1}$ reported that a high proportion of so-called permanent or semi-permanent hair dyes, which contain various aromatic amines or aromatic nitro compounds, were mutagenic in laboratory tests using a special strain of Salmosella typhimurium. The most active constituent tested was 2,4diaminotoluene, which is carcinogenic in rats ${ }^{2}$ and until recently was a constituent of certain hair dyes. Since many known carcinogens are mutagenic in this test system, ${ }^{3}$ it was suggested that these hair dyes might be carcinogenic in man, ${ }^{1}$ particularly since systemic absorption occurs from their use. ${ }^{4}$ Moreover, breast cancer was specifically mentioned in this connection. ${ }^{1}$ Epidemiological studies were indicated to test this suggestion since available human data were scanty.

Women hairdressers are relevant here, since their work often exposes them to these dyes and it is also likely that they use them on their own hair more than the average. An excess of breast cancer (but of no other listed site of cancer) has been recorded among single women hairdressers in the occupational mortality analyses of the Registrar General. ${ }^{5}$ ' In 1959-63 there were 21 deaths in women in this group aged under 65 compared with 12 expected on the national age-specific rates for single women; the corresponding figures in 1949-53 were 13 observed and nine expected. Data are not available for married hairdressers, as they are classified by their husbands' occupations. Since there is

DHSS Cancer Epidemiology and Clinical Trials Unit, Department of the Regius Professor of Medicine, University of Oxford, Oxford

L J KINLEN, MB, MRCP, Cancer Research Campaign-Gibb fellow

R HARRIS, BSC, research assistant

A GARROD, SRN, research assistant

K RODRIGUEZ, BA, research assistant also some evidence of an increase in mortality from breast cancer in recent decades, during which use of the hair dyes in question has increased, a case-control study of hair dye use by patients with breast cancer was carried out in the Oxford area in 1975-6.

\section{Methods}

One hundred and ninety-one women with breast cancer were questioned by experienced interviewers ( $R H, A G$, and $K R$ ) in the Radcliffe Infirmary, John Radcliffe Hospital, or Churchill Hospital in 1975-6, and details obtained about their use (prior to diagnosis) of hair care preparations, whether applied by a hairdresser or at home. These details included the type of preparation (permanent dye, semipermanent dye, bleach, rinse, lacquer, or perm), the name of the brand if known, the period in which it was used, and the frequency of application. Most patients ( $72 \%$ ) were interviewed within two years of breast cancer being diagnosed, $83 \%$ within three years, and all within five years.

Similar details were collected from 561 matched controls, who comprised 506 inpatients or outpatients at the above hospitals who did not have malignant disease and 55 women selected from an age-sex register in a general practice and interviewed at home. The patients were matched for age (within three years), marital status, and social class. Details of the diagnoses in the controls are shown in table I. Most patients had three matched controls but a few had two or four, and two had only one suitable control. Data on certain gynaecological and obstetric factors known to affect the risk of breast cancer were also collected, such as age at menopause and age at delivery of first live or stillborn child. Details of smoking habits were also obtained. Hair care preparations were identified in terms of their general type (permanent, semi-permanent, etc) by reference, in the case of named preparations, to an index compiled from information supplied by the Toilet Preparations Federation, local pharmacists, and hairdressing salons. In other cases the type was identified by appropriate questions prepared after consultation with local hairdressers and checked against material supplied by the manufacturers.

\section{Results}

The numbers of patients with breast cancer and controls who had used each of the main types of hair care preparations are shown in table II. There was no significant difference in the use of any preparation between the patients before diagnosis and the controls in the corresponding period. (Each control was assumed to have a date of diagnosis the same as that of her matched patient.) The major diagnostic groups among the controls (see table I) were examined separately in terms of their use of permanent or semi-permanent dyes but no significant differences were found.

In view of the fact that mutagenic compounds are present in a high proportion of permanent and semi-permanent hair dyes, ${ }^{1}$ these were considered collectively in table III, which shows an analysis by duration of use. Again there was no appreciable difference between the index and control groups in their use of this group of hair dyes.

TABLE I-Diagnoses in the 561 controls

\begin{tabular}{|c|c|c|c|}
\hline & $\begin{array}{c}\text { No of } \\
\text { controls }\end{array}$ & & $\begin{array}{l}\text { No of } \\
\text { controls }\end{array}$ \\
\hline $\begin{array}{l}\text { Gynaecological disorders } \\
\text { Diseases of digestive system } \\
\text { Circulatory diseases } \\
\text { Allergic, endocrine, and } \\
\text { metabolic diseases }\end{array}$ & $\begin{array}{r}177 \\
69 \\
72 \\
23\end{array}$ & $\begin{array}{l}\text { Ocular disorders } \\
\text { Other disorders (skin, joint, } \\
\text { genitourinary, infective, } \\
\text { etc) } \\
\text { Community controls }\end{array}$ & $\begin{array}{l}94 \\
71 \\
\\
55\end{array}$ \\
\hline
\end{tabular}


A matched set analysis confirmed the absence of any significant difference between the study groups. ${ }^{7}$ In view of the possibility of a long latent interval for the induction of breast cancer an examination was made of hair dye use over four years and over nine years before the diagnosis. This also showed no significant differences, with risks relative to people who had never used dyes of 1.03 and 0.95 respectively (table III). The frequency of application of these hair dyes by those who used them was similar in the two groups. There was also no difference in the use of named brands containing diamines by the patients and controls-for example, in the period over four years before diagnosis the risk relative to those who had never used dyes was 0.99 .

There was no evidence of any difference in the frequency of use of permanent and semi-permanent dyes among women in different social classes. Among women aged over 50, however, there was a significantly greater proportion of past or present smokers among the users $(63.0 \%$ of cases and controls combined) of these dyes than among non-users (43.5). This difference was not apparent among those aged under 50 $(57.9 \%$ and $53.8 \%$ respectively). Among parous controls there was a significant association between age at first pregnancy and hair dye use; those who had their first pregnancy in the age group 15-19 had the highest prevalence of hair dye use (table IV). An analysis adjusted for age at diagnosis confirmed this association $\left(\chi^{2}\right.$ trend $=7.95$; $\mathbf{P}<0.01)$. Of the 12 women in the study who were or had previously been hairdressers eight had used the hair dyes in question. There was no relation between the age at menopause and the use of permanent or semi-permanent hair dyes.

TABLE II-Proportions of patients and controls who had ever used types of hair care preparations

\begin{tabular}{l|c|c}
\hline \multicolumn{1}{c|}{ Preparation } & $\begin{array}{c}\text { No ("o) of } \\
\text { patients with } \\
\text { breast cancer }\end{array}$ & $\begin{array}{c}\text { No (o, of } \\
\text { controls }\end{array}$ \\
\hline $\begin{array}{l}\text { Permanent dye } \\
\text { Permanent dye and bleach }\end{array}$ & $33(17 \cdot 3)$ & $92(16 \cdot 4)$ \\
$\begin{array}{l}\text { Semi-permanent dye } \\
\text { Bleach only }\end{array}$ & $15(7 \cdot 9)$ & $40(7 \cdot 1)$ \\
Permanent wave & $37(19 \cdot 4)$ & $112(20 \cdot 0)$ \\
Colour rinse & $5(2 \cdot 6)$ & $16(2 \cdot 9)$ \\
Lacquer & $138(72 \cdot 3)$ & $425(75 \cdot 8)$ \\
\multicolumn{1}{c|}{ Total } & $37(19 \cdot 4)$ & $93(16 \cdot 6)$ \\
\hline \multicolumn{1}{c|}{$127(66 \cdot 5)$} & $395(70 \cdot 4)$ \\
\hline & $191(100)$ & $561(100)$ \\
\hline
\end{tabular}

\section{Discussion}

About one-third of the women in the Oxford area in the present study had used permanent or semi-permanent hair dyes, but there was no appreciable difference in the use of these dyes between women with breast cancer and matched controls. The proportion of hair dye users and the number of women studied were such that if any use of hair dyes had caused a twofold increased risk of breast cancer then this would have stood a $99 \%$ chance of being detected in a study of the present size. If hair dyes had caused breast cancer after an interval of four to five years there were enough women who had used dyes at this interval before diagnosis to have given a $98 \%$ chance of detecting
TABLE IV-Numbers of hair dye (permanent and semi-permanent) users among patients and controls according to age at first pregnancy

\begin{tabular}{c|c|c}
\hline $\begin{array}{c}\text { Age at 1st pregnancy } \\
\text { (years) }\end{array}$ & $\begin{array}{c}\text { No ( }{ }^{\circ} \text { o) of breast } \\
\text { cancer patients }\end{array}$ & $\begin{array}{c}\text { No }(\%) \text { of } \\
\text { controls }\end{array}$ \\
\hline $15-19$ & $2(33 \cdot 3)$ & $22(64 \cdot 7)$ \\
$20-24$ & $17(37 \cdot 0)$ & $70(39 \cdot 6)$ \\
$25-29$ & $23(42 \cdot 6)$ & $61(40 \cdot 7)$ \\
230 & $18(38 \cdot 3)$ & $25(25 \cdot 5)$ \\
No pregnancy & $13(34 \cdot 2)$ & $35(34 \cdot 3)$ \\
\hline Total & $73(38 \cdot 2)$ & $213(38 \cdot 0)$ \\
\hline
\end{tabular}

a twofold increased risk. Similar calculations indicate that such an increase in risk would have been detected with a likelihood of $85^{\circ} \%$ if the latent interval had been 9-10 years, but too few women had used these hair dyes more than 14-15 years before diagnosis to make any useful comment (five patients; 12 controls). The association between age at first pregnancy and hair dye use was unexpected and was not removed by controlling for age at diagnosis.

A recent report from New York $^{8}$ that 87 out of 100 patients with breast cancer had been "long time users of hair colouring" but only $26 \%$ of an unstated number of women without breast cancer of similar age were "regular users of permanent hair dyes" cannot be evaluated. Details of hair dye use by patients with breast cancer were sometimes obtained from relatives though apparently not in the case of the controls. No information was provided about the selection of patients or controls except that the patients with breast cancer were seen over a period of years in private and consulting practice. Our study would certainly have detected an increase of the order implied by the New York report.

It is difficult to account for the raised standardised mortality ratios (SMRs) in single hairdressers in 1949-53 and 1959-63, which in part prompted this study. Discrepancies in the description of occupation at registration of death and at the census can influence the SMR, but the fact that there were fewer deaths from all causes under the age of 65 (142 in 1959-63 and 198 in 1959-63) than expected (182 and 258 respectively) does not suggest that the breast cancer excess can be explained in this way. The number of hairdressers in our study was too small to provide useful data on this question, though the proportion of hairdressers was no higher among the patients with breast cancer (two) than among the controls (10).

The usefulness of the Ames's mutagenecity test in identifying human carcinogens is still uncertain. Nevertheless, the fact that few known carcinogens give a negative result obliges us to pay attention to any agents which are positive on this test and to which there is appreciable human exposure. This is particularly the case with permanent and semi-permanent hair dyes both because they are strongly mutagenic on this test and because many people use them. Further epidemiological studies are indicated in relation to cancers of different sites. In view of our finding of a higher proportion of cigarette smokers among users

TABLE III-Use of permanent and semi-permanent hair dyes according to length of use in different periods

\begin{tabular}{|c|c|c|c|c|c|c|c|c|c|}
\hline \multirow{3}{*}{$\begin{array}{l}\text { Length of use } \\
\text { (years) }\end{array}$} & \multicolumn{9}{|c|}{ Dyes used: } \\
\hline & \multicolumn{3}{|c|}{ At any time before diagnosis } & \multicolumn{3}{|c|}{ Over 4 years before diagnosis } & \multicolumn{3}{|c|}{ Over 9 years before diagnosis } \\
\hline & $\begin{array}{c}\text { No }(\%) \text { of } \\
\text { patients with } \\
\text { breast cancer }\end{array}$ & $\begin{array}{l}\text { No }\left({ }_{0}^{0}\right) \text { of } \\
\text { controls }\end{array}$ & $\begin{array}{l}\text { Risk ratio } \\
\text { relative to } \\
\text { never used }\end{array}$ & $\begin{array}{c}\text { No }(\%) \text { of } \\
\text { patients with } \\
\text { breast cancer }\end{array}$ & $\begin{array}{l}\text { No }\left({ }^{\circ}{ }_{0}\right) \text { of } \\
\text { controls }\end{array}$ & $\begin{array}{l}\text { Risk ratio } \\
\text { relative to } \\
\text { never used* }\end{array}$ & $\begin{array}{c}\text { No }(\%) \text { of } \\
\text { patients with } \\
\text { breast cancer }\end{array}$ & $\begin{array}{l}\text { No }(\%) \text { of } \\
\text { controls }\end{array}$ & $\begin{array}{l}\text { Risk ratio } \\
\text { relative to } \\
\text { never used* }\end{array}$ \\
\hline $\begin{array}{c}<1 \\
1-4 \\
5-9 \\
10-14 \\
15-19 \\
20 \\
\text { Not known } \\
\text { Total who had } \\
\text { used dyes }\end{array}$ & $\begin{array}{c}10(5 \cdot 2) \\
31(16 \cdot 2) \\
17(8 \cdot 9) \\
11(5 \cdot 8) \\
2(1 \cdot 1) \\
2(1 \cdot 1) \\
0 \\
73(38 \cdot 2)\end{array}$ & $\begin{array}{c}44(7 \cdot 8) \\
68(12 \cdot 1) \\
57(10 \cdot 2) \\
26(4 \cdot 6) \\
9(1 \cdot 6) \\
8(1 \cdot 4) \\
1(0 \cdot 2) \\
213(38 \cdot 0)\end{array}$ & $\begin{array}{l}0.67 \\
1.34 \\
0.88 \\
1.25 \\
0.66 \\
0.74 \\
1.01\end{array}$ & $\left\{\begin{array}{l}10(5 \cdot 2) \\
23(12 \cdot 0) \\
12(6 \cdot 3) \\
7(3 \cdot 7) \\
0 \\
52(27 \cdot 2)\end{array}\right.$ & $\begin{array}{c}34(6 \cdot 1) \\
58(10 \cdot 3) \\
34(6 \cdot 1) \\
24(4 \cdot 3) \\
1(0 \cdot 2) \\
151(26 \cdot 9)\end{array}$ & $\begin{array}{l}0.87 \\
1.17 \\
1.04 \\
0.86\end{array}$ & $\begin{array}{c}5(2 \cdot 6) \\
15(7 \cdot 9) \\
2(1 \cdot 1) \\
5(2 \cdot 6) \\
0 \\
27(14 \cdot 1)\end{array}$ & $\begin{array}{c}26(4 \cdot 6) \\
32(5 \cdot 7) \\
11(2 \cdot 0) \\
13(2 \cdot 3) \\
1(0 \cdot 2) \\
83(14 \cdot 8)\end{array}$ & $\begin{array}{l}0.56 \\
1.37 \\
0.53 \\
1.12\end{array}$ \\
\hline
\end{tabular}

*In corresponding period. 
of these hair dyes it will be important to take account of smoking habits in any such studies of smoking-related cancers, particularly in view of a recent report suggesting that beauticians have an increased risk of lung cancer. ${ }^{9}$

We thank the consultants who allowed us to interview patients under their care, and the Toilet Preparations Federation and the manufacturers of hair dyes, who helped us by providing information about hair care preparations. We also thank Mr Paul Humphreys, who helped in the analysis of this study, and Mr Peter Smith, Mr Julian Peto, and Sir Richard Doll for their helpful comments.

ADDENDUM-The Registrar General has informed us that the latest (unpublished) occupational mortality analysis for 1970-2 shows no appreciable excess of breast cancer in single female hairdressers aged under 65 years-eight observed, seven expected (OPCS, by permission).

\section{References}

1 Ames, B N, Kammen, H O, and Yamasaki, E, Proceedings of the National Academy of Sciences of the United States of America, 1975, 72, 2423.

2 Ito, N, et al, Cancer Research, 1969, 29, 1137.

${ }^{3}$ McCann, J, and Ames, B N, Proceedings of the National Academy of Sciences of the United States of America, 1976, 73, 950

${ }^{4}$ Kiese, M, and Rascher, E, Toxicology and Applied Pharmacology, 1968, 13, 325.

${ }^{5}$ Registrar General's Decennial Supplement, England and Wales 1951, Occupational Mortality, part 2. London, HMSO, 1957.

${ }^{6}$ Registrar General's Decennial Supplement, England and Wales 1961, Occupational Mortality Tables. London, HMSO, 1971.

${ }^{7}$ Pike, M C, and Morrow, R H, British fournal of Preventive and Social Medicine, 1970, 24, 42.

8 Shafer, N, and Shafer, R W, New York State fournal of Medicine, 1976, 76, 394.

${ }^{9}$ Garfinkel, J, Selvin, S, and Brown, S M, fournal of the National Cancer Institute, 1977, 58, 141.

(Accepted 10 fune 1977)

\section{SHORT REPORTS}

\section{Superior vena caval obstruction complicating fibreoptic gastroscopy}

Here I report a case of superior vena caval (SVC) obstruction after fibreoptic gastroscopy in a patient with an unsuspected bronchial carcinoma, who presented with an acute gastrointestinal bleed. To date there are no other reported cases of this unusual complication.

\section{Case report}

An 83-year-old Polish woman was admitted to hospital after a three-day history of melaena. She was known to have a hiatus hernia, which had been diagnosed at barium meal, when she presented with a haematemesis nine years previously. She had otherwise been well and symptom free until the current episode. She did, however, admit to a one stone $(6.3 \mathrm{~kg})$ weight loss over a six-month period and was noted to be a heavy smoker. On examination, apart from moderate obesity, she had no abnormal physical signs, but rectal examination confirmed melaena stools. There was no haemodynamic disturbance. The haemoglobin concentration on admission was $9.7 \mathrm{~g} / \mathrm{dl}$ with normal red cell indices. The urea was $7.8 \mathrm{mmol} / 1(48 \mathrm{mg} / 100 \mathrm{ml})$ and electrolytes normal. The chest $x$-ray film showed appreciable unfolding of the aortic arch but was otherwise normal and she had a normal electrocardiogram. A blood transfusion was started and she was referred for endoscopy. A premedication of $7.5 \mathrm{mg}$ diazepam was given intravenously.

The instrument, which was a forward viewing Olympus oesophagogastroduodenoscope, was passed without difficulty through a normal upper oesophagus. A large sliding hiatus hernia with moderate oesophagitis, not actively bleeding, was noted. The stomach contained a large pool of blood with multiple gastric erosions. At this stage the patient was noted to be having some respiratory difficulties and the endoscopy was stopped. She continued to have difficulty in breathing and after 15 minutes was considered to require ventilation. When intubated, no evidence of aspiration was found, but she was then noted to have the clinical appearance of SVC obstruction. This was supported by a high central venous pressure CVP reading $(30 \mathrm{~cm})$ from a catheter high in the SVC. Although the possibility that this could be due to a haematoma induced at the time of insertion of the subclavian CVP line was considered, it was felt to be more likely to be due to hitherto unsuspected bronchial carcinoma and treatment with parenteral steroids was instituted. It was possible to wean her off the ventilator after 24 hours, but her general condition remained poor and she died 48 hours later.

Necropsy showed a proximal bronchial carcinoma of the right upper main bronchus invading the mediastinum and pericardium and causing complete superior vena caval obstruction. Since there were no clinical signs of this at the initial clinical examination, it was assumed to have been precipitated by oedema caused by the trauma of endoscopy.

\section{Discussion}

The complication rate for routine upper gastrointestinal endoscopy is low, although it is recognised that emergency endoscopy is more hazardous. In a comprehensive review of complications in 23563 cases, based on a questionnaire from the British Society for Digestive Endoscopy ${ }^{1}$ and their own experience, ${ }^{2}$ Schiller and Prout found no report of SVC obstruction. SVC obstruction is an uncommon complication of carcinoma of the bronchus and there is usually an antecedent history of neck enlargement ${ }^{3}$ or pain ${ }^{4}$ in addition to the more usual symptoms of the carcinoma. This patient had no such complaints.

1 Schiller, K F R, Cotton, P B, and Salmon, P R, Gut, 1972, 13, 1027.

2 Schiller, K F R, and Prout, B J, Modern Topics in Gastrointestinal Endoscopy, edited by K F R Schiller, and P R Prout, p 147. London, Heinemann, 1976.

${ }^{3}$ Crofton, J, and Douglas, A, Respiratory Diseases. Oxford, Blackwell, 1975.

4 Stevens, A E, Lancet, 1963, 1, 1230.

(Accepted 6 April 1977)

King Edward Memorial Hospital, London W13

J DAWSON, BM, MRCP, medical registrar (present address: Hammersmith Hospital, London W 12 OHS)

\section{Microbial hazard of a bedside test}

We wish to draw attention to the microbial risks associated with a commonly performed bedside test. Kerry and Anderson described the use of a commercially available reagent, Clinitest Tablets (Ames Manufacturing Co Inc), to detect reducing substances in the faeces of children with gastroenteritis. ${ }^{1}$ A small outbreak of Salmonella typhimurium infection in a children's ward prompted us to investigate the possible microbiological hazards of this procedure.

\section{Outbreak, investigations, and results}

Case 1-A baby girl aged 2 months was admitted on 21 May 1976 for investigation of diarrhoea, and was barrier nursed. Stool culture taken on admission yielded a growth of Salmonella typhimurium, phage type DT32.

Case 2-A girl aged 6 months was admitted to a cubicle on 21 May 1976 with respiratory difficulties and a cyanotic attack. On 25 May she developed diarrhoea and was barrier nursed. $S$ typhimurium, phage type DT32, was isolated from stool specimens.

Examination of stool specimens from staff yielded $S$ typhimurium, phage types DT32, from the faeces of one nurse. It emerged that each stool from Case 1 had been examined for $\mathrm{pH}$ and reducing substances by the method of Kerry and Anderson, the colour reaction being noted, the contents dis- 